\title{
Renal Function Assessment in Adults with Recurrent Calcium Kidney Stone Disease
}

\section{Amir Hossein Milladipour ${ }^{1 *}$ and Mohsen Rezaei Hemami²}

1 Urology and Nephrology Research Center, Shohada-e-Tajrish Medical Center, Shahid Beheshti University of Medical Sciences, Tehran, Iran 2Department of Epidemiology and Biostatistics, School of Public Health, Tehran University of Medical Sciences, Tehran, Iran

\begin{abstract}
The prevalence of nephrolihiasis and chronic kidney disease has risen over the past three decades, we sought to determine if person with a history of kidney stones have lower renal function relative to non stone formers.

Methods: We conducted a case-control study utilizing 138 recurrent calcium kidney stone formers and 127 age and gender matched controls with no history of renal disease, all subjects were aged 30-55 years old, with no history of hypertension, diabetes mellitus, congestive heart failure and liver disease and also no urinary tract obstruction and medications can affect Glomerular Filtration Rate (GFR).

We estimated GFR by Modification of Diet in Renal Disease (MDRD) and Chronic Kidney Disease Epidemiology Collaboration (CKD-EP I) equations and categorized using cut points suggested by Kidney Disease Outcomes Quality Initiative (K/DOQI) guidelines.

Results: Mean GFR in case group and control group was: $80.17(18.45) \mathrm{ml} / \mathrm{min} / 1.73 \mathrm{~m}^{2}$ and $83.80(15.75) \mathrm{ml} /$ $\mathrm{min} / 1.73 \mathrm{~m}^{2}$ respectively (P value: 0.09 ). Distribution of subjects among stone formers in stage I, II, III was $59(42.8 \%)$, $71(51.4 \%)$ and $8(5.8 \%)$ and in control group was $67(52.8 \%), 59(46.4 \%)$ and $1(0.8 \%)$ respectively, (p: 0.03$)$. There was an inverse correlation between GFR and number of passed stone but there was no significant correlation between history of extracorporeal shock wave lithotripsy (ESWL) or percutaneous nephrolithotomy (PCNL) and estimated GFR.
\end{abstract}

Conclusion: Recurrent calcium stone disease may be associated with nephron damage and an increased risk of chronic kidney disease.

Keywords: Glomerular Filtration Rate; Chronic Kidney Disease; Kidney Stone

\section{Introduction}

Kidney stones are a common condition associated with significant morbidity, since up to $12 \%$ of men and $5 \%$ of women will have one symptomatic kidney stone by the age of 70 and recurrence rates are estimated at $50 \%[1]$.

Most people who experience an episode of stones will have at least one recurrence and some will suffer repeated bouts that may increase the likelihood of renal damage from obstruction or surgery [2]. Alarmingly, the incidence of Chronic Renal Insufficiency (CRI) is rising throughout the world [3]. With respect to patient outcomes, CRI patients suffer from an increased risk of mortality and cardiovascular disease relative to the general population $[4,5]$. While much is known about the pathogenesis and treatment of nephrolithiasis, the clinical consequences of stone disease remain relatively unidentified. In particular, little is known about the effect of stone disease on renal function. The hypothesis is that repeated transient obstruction from stone passage, treatments such as Extracorporeal Shock Wave Lithotripsy (ESWL), and possibly mineral deposits in the renal medulla may damage nephrons and reduce renal function [6-8].

We used data from a case-control study to measure associations between recurrent urinary calcium stones and loss of renal function.

\section{Methods}

We conducted a case-control study utilizing 138 cases with recurrent urinary calcium stones (based on history, radiologic studies and stone analysis) that were selected from our outpatient stone clinic and 127 community controls with no history of urinary stone.

All subjects were men, aged 30 to 55 years and also they had no established metabolic, gastrointestinal, Liver, cardiovascular, and endocrine disorders, they had no documented metabolic (such as diabetes mellitus), gastrointestinal, liver, cardiovascular (such as HTN and $\mathrm{CHF}$ ), or endocrinological disorders. We excluded all the patients with urinary tract anomalies or obstruction, urinary tract infection, first single stone presentation, obesity (Body Mass Index > 30), and those who were on medication that may affect GFR. Furthermore, those patients with the excretion of cystine crystals in their urine were also excluded. The study was approved by the medical ethics committee, and all of the subjects gave their informed consents. "Recurrent stone former" was defined as either a recurrent stone event or an increase in the stone size during the past five years confirmed by imaging modalities.

All subjects underwent metabolic evaluation, urine analysis and culture, kidney and urinary tract sonography. We estimated GFR by modification of Diet in Renal disease (MDRD) and Chronic Kidney Disease Epidemiology Collaboration (CKD-EP I) equations, $[9,10]$ and categorized using cut points suggested by K/DOQI guidelines: stage I $\left(\right.$ GFR $>90 \mathrm{ml} / \mathrm{min} / 1.73 \mathrm{~m}^{2}$ ) stage II (GFR: $60-89 \mathrm{~mL} / \mathrm{min} / 1.73 \mathrm{~m}^{2}$ ), stage III (GFR: $30-59 \mathrm{~mL} / \mathrm{min} / 1.73 \mathrm{~m}^{2}$ ), and we also adjusted GFR based on body surface area (BSA)( $\mathrm{ml} / \mathrm{min})$.

${ }^{*}$ Corresponding author: Amir Hossein Milladipour, Shohada-e-Tairish Medica Center, section of Nephrology and transplantation, tajish SQ., Tehran, Iran, Tel: 0912-157-2508, 021-22718001-8; Fax: 021-22718027; E-mail: amiladi@hotmail.com

Received February 27, 2012; Accepted May 14, 2012; Published May 16, 2012

Citation: Milladipour AH, Hemami MR (2012) Renal Function Assessment in Adults with Recurrent Calcium Kidney Stone Disease. J Nephrol Therapeut 2:121. doi:10.4172/2161-0959.1000121

Copyright: (c) 2012 Milladipour $\mathrm{AH}$, et al. This is an open-access article distributed under the terms of the Creative Commons Attribution License, which permits unrestricted use, distribution, and reproduction in any medium, provided the original author and source are credited. 


\section{Statistical Analysis}

The data was analyzed by using SPSS software version-17 (SPSS Inc, Chicago) for statistical analysis. GFR was expressed as Mean \pm $\mathrm{SD}$. We report Pearson correlation coefficient for investigating relation between GFR in two groups in all stages by using $t$ test, and regression analysis for correlation of GFR and "the number of passed stone, ESWL and PCNL". $p<0.05$ was considered statistically significant value.

\section{Results}

The mean age of all subjects was 40 years (range, $30-55$ years), all were male and white, there was no significant differences for age, BMI and serum creatinin in case and control groups (Table 1).

Estimation of GFR by MDRD and CKD-EPI equations and also modification of estimated GFR for BSA does not show significant differences between case and control groups (Table 2).

Categorization of estimated GFR using cut points suggested by K/ DOQI guidelines show that recurrent stone formers experience a down ward shift in the distribution of GFR, resulting in a higher proportion of persons in the lower - tail of the distribution of GFR, this finding is especially significant in estimated GFR by CKD-EPI equation modified by BSA ( $\mathrm{p}<0.03)$ (Figures $1-4)$.

There is a significant negative correlation between estimated GFR and number of passed stone $(r=-0.18, p=0.03)$, there is no significant correlation between history of ESWL or percutaneous nephrolithotomy (PCNL) and estimated GFR.

There is no significant difference of estimated GFR between case and control groups according to BMI, the estimated GFR in case and control group in subjects with BMI $<25 \mathrm{~kg} / \mathrm{m}^{2}$ were $83.49(17.71)$ and 89.76(18.14) $\mathrm{ml} / \mathrm{min}$ respectively (p:0.10), and in subjects with BMI > 25 were $92.21(23.12)$ and $95.49(19.24) \mathrm{ml} / \mathrm{min}$ respectively (p:0.31).

In our subjects the prevalence of stage $3 \mathrm{CKD}$ seems to be higher with the MDRD equation than CKD-EPI equation but is not significant.

\begin{tabular}{|c|c|c|c|}
\hline & $\begin{array}{c}\text { Case } \\
\text { Mean (SD) }\end{array}$ & $\begin{array}{c}\text { Control } \\
\text { Mean (SD) }\end{array}$ & P-Value \\
\hline Mean age, years & $40.82(5.22)$ & $39.48(6.50)$ & 0.09 \\
\hline Mean BMI, kg/m² & $26.53(2.82)$ & $25.85(3.06)$ & 0.06 \\
\hline Mean Serum creatinine mg/dL & $1.16(0.26)$ & $1.13(0.18)$ & 0.36 \\
\hline No. of passed stone & $10.85(16.91)$ & - & - \\
\hline HX of ESWL & $101(75 \%)$ & - & - \\
\hline HX of PCNL & $46(33 \%)$ & - & - \\
\hline
\end{tabular}

Table 1: Selected characteristics of 138 recurrent stone former and 127 contro groups.

\begin{tabular}{|c|c|c|c|}
\hline GFR calculation method & $\begin{array}{l}\text { Case (No.138) } \\
\text { Mean (SD) }\end{array}$ & $\begin{array}{c}\text { Control } \\
\text { (No.127) } \\
\text { Mean (SD) }\end{array}$ & P-Value \\
\hline MDRD (mL/min/1.73m²) & $77.66(19.03)$ & $79.60(15.68)$ & 0.34 \\
\hline CKD-EPI (ml/min/1.73m²) & $80.17(18.45)$ & $83.80(15.75)$ & 0.09 \\
\hline MDRD adjusted by BSA (ml/min) & $86.55(22.23)$ & $88.77(19.30)$ & 0.39 \\
\hline CKD-EPI adjusted by BSA ( $\mathrm{ml} / \mathrm{min})$ & $89.49(21.89)$ & 93.41(18.99) & 0.12 \\
\hline
\end{tabular}

Table 2: Comparison of estimated GFR in recurrent stone former and control groups in different calculation methods.

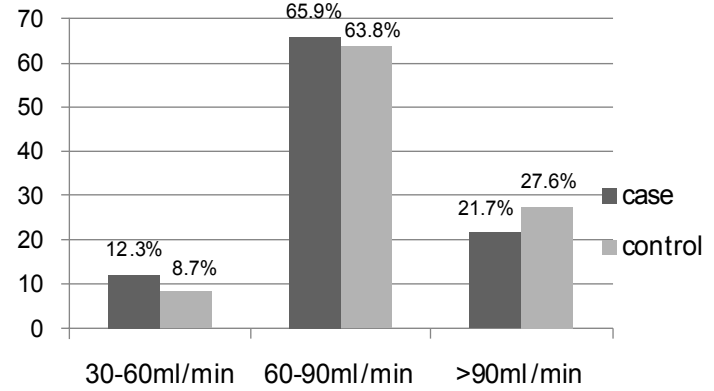

Figure 1: Comparison of GFR in 138case and 127control groups (percent) based on MDRD ( $\mathrm{ml} / \mathrm{min} / 1.73 \mathrm{~m} 2)$.

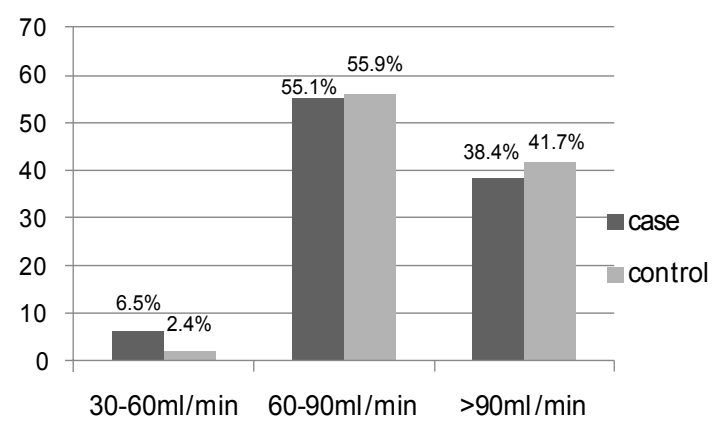

Figure 2: Comparison of GFR in 138case and 127control groups (percent) based on modified MDRD ( $\mathrm{ml} / \mathrm{min})$.

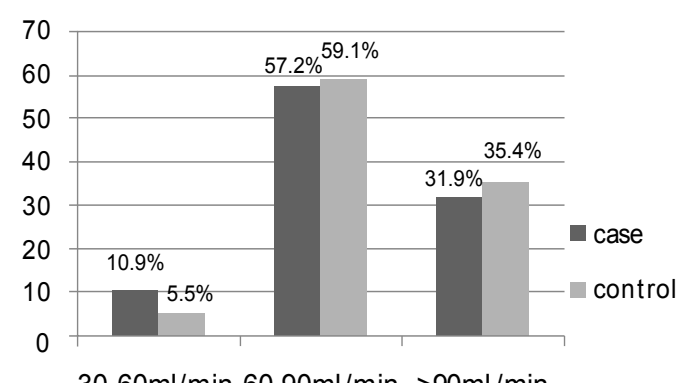

$30-60 \mathrm{ml} / \mathrm{min} 60-90 \mathrm{ml} / \mathrm{min}>90 \mathrm{ml} / \mathrm{min}$

Figure 3: Comparison of GFR in 138case and 127control groups (percent) based on CKD-EPI (ml/min/1.73m2).

\section{Discussion}

Our data suggest that recurrent kidney stones are associated with an increased risk of chronic kidney disease. In this study we exclude confounding factors and important risk factors for CKD in all subjects such as; history of HTN, DM, glomerulonehritis, cardiovascular disease, drugs and other underlying diseases. Even though there was a significant correlation between the number of passed stone and loss of GFR, there was no significant correlation between ESWL and PCNL procedures and loss of GFR. There was no significant differences in terms of GFR between recurrent stone former and control groups in $\mathrm{BMI}>25 \mathrm{~kg} / \mathrm{m}^{2}$ and $\mathrm{BMI}<25 \mathrm{~kg} / \mathrm{m}^{2}$ subjects.

Gillen and associates [11] have reported that the association between history of stones and estimated GFR depends on Body Mass Index (BMI) $(\mathrm{P}=0.004)$. Mean estimated GFR in stone formers with a $\mathrm{BMI}>/=27 \mathrm{~kg} / \mathrm{m}^{2}$ was $3.4 \mathrm{~mL} / \mathrm{min} / 1.73 \mathrm{~m}^{2}$ lower than that of similar 


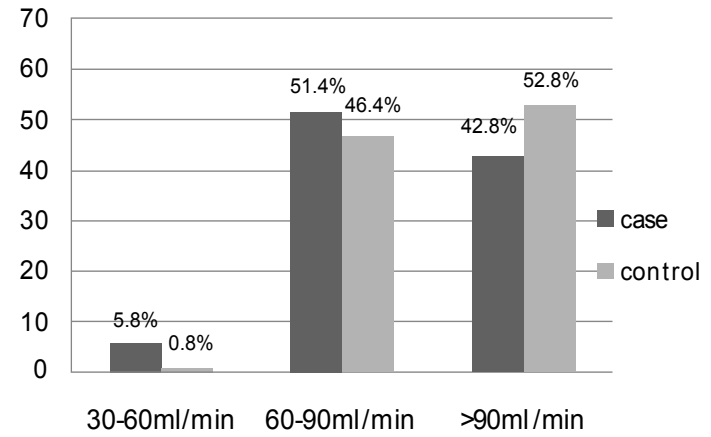

Figure 4: Comparison of GFR in 138case and 127control groups (percent) based on modified CKD-EPI ( $\mathrm{ml} / \mathrm{min})$.

nonstone formers $(95 \% \mathrm{CI}-5.8,-1.1)(\mathrm{P}=0.005)$. No difference was found among persons with a BMI $<27 \mathrm{~kg} / \mathrm{m}^{2}$. The probability of an overweight stone former having an estimated GFR between 30 and $59 \mathrm{~mL} / \mathrm{min} / 1.73 \mathrm{~m}^{2}$ relative to a GFR above $90 \mathrm{~mL} / \mathrm{min} / 1.73 \mathrm{~m}^{2}$ was nearly twice that of a similar nonstone former [relative risk ratio (RRR) $=1.87,95 \%$ CI $1.06,3.30][11]$.

In our study BMI in all subjects were less than $30 \mathrm{~kg} / \mathrm{m}^{2}$ and GFR was not different between case and control groups in BMI less or more than $25 \mathrm{~kg} / \mathrm{m}^{2}$.

In a case-control study utilizing 548 hospital cases and 514 age, race and gender matched has been revealed $16.8 \%$ of cases( with CKD) and $6.4 \%$ of controls with reported history of kidney stones, the odds ratios for chronic kidney disease (overall), diabetic nephropathy and interstitial nephritis for patients with kidney stones were 1.9 (95\% CI: 1.1, 3.3), 2.5 (95\% CI: 0.87, 7.0) and 3.4 (95\% CI: 1.5, 7.4), respectively [2].

In the study of Marangella et al. [12] they investigated the occurrence of chronic renal insufficiency in 171 patients with severe idiopathic calcium stone disease. The GFR level was in part predicted by the age of patients; however, stone disease was shown to induce a clear-cut influence in accelerating the natural worsening of GFR with age in a Case-control study for evaluation of risk factors for chronic kidney disease in persons with kidney stones, cases with CKD were significantly more likely $(\mathrm{P}<0.05)$ than controls to have had a history of diabetes ( $41.5 \%$ vs. $17.0 \%)$, hypertension ( $71.7 \%$ vs. $49.1 \%)$, frequent urinary tract infections ( $22.6 \%$ vs. $6.6 \%)$, struvite stones ( $7.5 \%$ vs. $0 \%)$, ileal conduits, and obesity (BMI $>30)$, Although there was no evidence that shock wave lithotripsy was more common among kidney stone patients with CKD, open lithotomy was more prevalent (OR 2.18), It is not known if patients with diabetes or hypertension and kidney stones are more likely to develop CKD than patients with diabetes or hypertension but without kidney stones [13].

Few studies have addressed the problem of renal function loss in idiopathic calcium nephrolithiasis. In a survey of 2,000 patients, only 33 patients (1.7\%) experienced low- to moderate-grade RI [14].

The prevalence of stage $3 \mathrm{CKD}$ is significantly higher with the MDRD study equation than CKD-EPI (11.04 vs. 7.98\%) [9].

The current study suggests that recurrent calcium stone disease may be associated with nephron damage and an increased risk of chronic kidney disease.

\section{Acknowledgements}

We thank all the medical personnel help in conducting this study. This study was sponsored by Urology, Nephrology Research Center, Shahid Behesht University of Medical Sciences, Tehran, Iran.

\section{References}

1. Stamatelou KK, Francis ME, Jones CA, Nyberg LM, Curhan GC, et al. (2003) Time trends in reported prevalence of kidney stones in the United States: 19761994. Kidney Int 63: 1817-1823.

2. Vupputuri S, Soucie JM, McClellan W, Sandler DP (2004) History of Kidney Stones as a Possible Risk Factor for Chronic Kidney Disease. Ann Epidemio 14: 222-228.

3. Stengel B, Billon S, Van Dijk PC, Jager KJ, Dekker FW, et al. (2003) Trends in the incidence of renal replacement therapy for end-stage renal disease in Europe, 1990-1999. Nephrol Dial Transplant 18: 1824-1833.

4. Levin A, Foley RN (2000) Cardiovascular disease in chronic renal insufficiency Am J Kidney Dis 36: S24-S30.

5. Zabetakis PM, Nissenson AR (2000) Complications of chronic rena Insufficiency: Beyond cardiovascular disease. Am J Kidney Dis 36: S31-S38.

6. Delvecchio F, Auge BK, Munver R, Brown SA, Brizuela R, et al. (2003) Shock wave lithotripsy causes ipsilateral renal injury remote from the focal point: the role of regional vasoconstriction. J Urol 169: 1526-1529.

7. Sheir KZ, Gad HM (2003) Prospective study of the effects of shock wave lithotripsy on renal function: role of post-shock wave lithotripsy obstruction. Urology 61: 1102-1106

8. Evan AP, Lingeman JE, Coe FL, Parks JH, Bledsoe SB, et al. (2003) Randall's plaque of patients with nephrolithiasis begins in basement membranes of thin loops of Henle. J Clin Invest 111: 607-616.

9. Delanaye P, Cavalier E, Mariat C, Maillard N, Krzesinski JM (2010) MDRD or CKD-EPI study equations for estimating prevalence of stage 3 CKD in epidemiological studies: which difference? Is this difference relevant? BMC Nephrol 11: 8

10. Silveiro SP, Araújo GN, Ferreira MN, Souza FD, Yamaguchi HM, et al. (2011) Chronic Kidney Disease Epidemiology Collaboration (CKD-EPI) Equation Pronouncedly Underestimates glomerular Filtration Rate in Type 2 Diabetes. Diabetes Care 11: 2353-2355.

11. Gillen DL, Worcester EM, Coe FL (2005) Decreased renal function among adults with a history of nephrolithiasis: a study of NHANES III. Kidney Int 67 : 685-690.

12. Marangella M, Bruno M, Cosseddu D, Manganaro M, Tricerri A, et al. (1990) Prevalence of Chronic Renal Insufficiency in the Course of Idiopathic Recurren Calcium Stone Disease: Risk Factors and Patterns of Progression. Nephron 54: $302-306$

13. Saucier NA, Sinha MK, Liang KV, Krambeck AE, Weaver AL, et al. (2010) Risk factors for CKD in persons with kidney stones: a case-control study in Olmsted County, Minnesota. Am J Kidney Dis 55: 61-68.

14. Gambaro G, Favaro S, D'Angelo A (2001) Risk for Renal Failure in Nephrolithiasis. Am J Kidney Dis 37: 233-243. 